\title{
Fragmentos da história: os xetá no Projeto Memória Indígena
}

\author{
Ana Clara Ferruda Zilli
}

Edilene Coffaci De Lima ${ }^{2}$

Recebido em maio de 2019

Aceito em outubro de 2019

\section{RESUMO}

De meados de 1985 a 1989 esteve em desenvolvimento o Projeto Memória Indígena (PMI). Através de entrevistas, visitas às Terras Indígenas, levantamentos bibliográficos e documentais, o projeto visava recuperar e recontar as histórias de vida dos grupos indígenas localizados no estado do Paraná. Parte do material resultante integra, atualmente, o acervo do Museu de Arqueologia e Etnologia da UFPR. Embasada em registros auditivos desse acervo, este artigo objetiva discutir a presença do povo Xetá no PMI. Essas narrativas apresentam o processo de rememoração das trajetórias individuais e coletivas, vivenciadas pelos interlocutores Xetá, durante e após o contato violento com os brancos, processo que resultou no desmembramento, exílio e genocídio desse povo. Se o os pesquisadores do PMI pensavam que documentavam a extinção dos Xetá, hoje, seu material atesta justamente o contrário: sua existência e resistência.

Palavras-chave: Xetá; Projeto Memória Indígena; história

\section{Fragments of history: the xetá in the Projeto Memória Indígena (Indigenous Memory Project)}

\begin{abstract}
The Projeto Memória Indígena (Indigenous Memory Project) (PMI) was developed between 1985 and 1989. Through interviews, visits to Indiginous Land, bibliographic and documental collections, the project aimed to rescue and relate the lifestories from indiginous groups located within the Paraná state region. Part of the material collected now, costitutes the collection of the Museum of Archeology and Anthropology of the UFPR. Based in sound records from the collection, this article aims to discuss the presence of the Xetá people. These narratives present the process of remembrance of collective and individual trajetories, experienced during and after the contact with the white people, process that resulted in genocide, dismemberment and exile of the Xetá. If PMI researches thought they documented the extintion of the Xetá, today, their material attests just the opposite: their existence and resistance.
\end{abstract}

Keywords: Xetá; Projeto Memória Indígena; history

decorrer da década de 1940, a região da Serra dos Dourados, localizada no noroeste

do estado do Paraná, foi marcada pela intensificação de uma política colonizadora que

\footnotetext{
${ }^{1}$ Graduada em Ciências Sociais pela UFPR, quando foi bolsista de IC do CNPq. Atualmente é mestranda em Antropologia Social pela UFSC. E-mail: anaclarafzilli@gmail.com

2 Professora do Departamento de Antropologia e do Programa de Pós-Graduação em Antropologia da UFPR. Pesquisadora PQ2 do CNPq. E-mail: edilene.c.lima@gmail.com
} 
visava ocupar esses territórios através de uma narrativa hegemônica de "terras demograficamente vazias” (MOTA, 1998). Na década de 1950 essa região viria a ser alvo de um boom colonizador (LIMA; PACHECO, 2017) e da fragmentação das terras, estas loteadas e comercializadas por Companhias de Colonização cujo objetivo era expandir a fronteira agrícola da cafeicultura, que, em seu apogeu, passara antes pela região de Londrina e Maringá, mais ao norte do estado.

A notícia de segmentação das terras do noroeste do Paraná e a presença de índios ditos "primitivos" na mata da Serra dos Dourados (SILVA, 1998), circulou no início da década de 1950, entre pesquisadores, funcionários do Serviço de Proteção ao Índio (SPI) e foi amplamente divulgada em jornais locais, nacionais e internacionais (LEITE, 2019). Esses indígenas viriam a ser conhecidos como Xetá, um povo tupi que, apesar de acossado em seu próprio território até o final da década de 1940, conseguiu manter-se afastado de um contato sistemático com os não-indígenas e foi o último povo a ser contatado no sul do Brasil (LIMA, 2016).

Estabelecido o contato com os brancos, no intervalo de uma década, entre 1950 e 1960, os Xetá foram reduzidos a poucos sobreviventes, "extraviados” (LIMA, 2018, p. 576) e "jogados ao esquecimento" ( $\mathrm{CNV}, 2014$, p.220). Após serem desterrados, os poucos sobreviventes foram distribuídos pelos agentes estatais para morarem em diferentes reservas indígenas, como então se chamavam, no Paraná e em Santa Catarina - e talvez mesmo no atual estado do Mato Grosso do Sul (outrora Mato Grosso). De forma veloz, foram tidos como extintos pelo Estado, pela literatura antropológica e pela sociedade nacional como um todo. Vivendo cada um em diferentes localidades, permaneceram separados por aproximadamente 40 anos, muitos deles sem saberem da existência de outros parentes vivos (SILVA, 1998).

Atualmente o povo Xetá vem lutando pela demarcação de seu antigo território Xetá no noroeste do Paraná. Somam um pouco mais de 200 pessoas, a maior parte delas moradoras da Terra Indígena de São Jerônimo da Serra, no Paraná, e os demais dispersos em diferentes cidades, como antes mencionado.

Na Tese IX Sobre o conceito de história (1987), Walter Benjamin apresenta a metáfora do "anjo da história”, representado no quadro Angelus Novus de Paul Klee, cujos "olhos estão escancarados, sua boca dilatada, suas asas abertas" (BENJAMIN, 
1987, p.183), seu rosto dirigido ao passado e a tempestade impelindo-o irresistivelmente ao futuro. Dessa forma, o "anjo da história”, ao mesmo tempo em que se volta ao passado para tentar acordar os mortos e juntar os fragmentos, vê-se arremessado pelo progresso que sopra do paraíso. (op.cit. 226).

Esse passado observado apresenta lacunas da história que não permitem reconstrui-lo tal como se deu. Conforme os cacos da história, quebrados e dispersos no passado, aos quais o anjo de Benjamin direciona o olhar, este artigo, que é fruto do trabalho de conclusão de curso em Ciências Sociais pela Universidade Federal do Paraná (ZILLI, 2018), com orientação e parceira de Edilene Coffaci de Lima, objetiva pensar os fragmentos da história presentes nas narrativas dos e sobre os Xetá apresentadas ao Projeto Memória Indígena.

\section{O Projeto Memória Indígena}

Ultrapassado o final da década de 1970, quando o movimento indígena brasileiro alcançou alta repercussão e diante de um contexto nacional de defesa dos direitos indígenas (CARNEIRO DA CUNHA, 2009, p.245), foi criado em 1985 o Projeto Memória Indígena (doravante PMI), pela professora e antropóloga da Universidade Federal do Paraná, Maria Lígia Moura Pires, e a antropóloga do Museu Paranaense, Lucia Helena O. Cunha. Iniciado em agosto do mesmo ano, a realização da pesquisa contou ainda com a antropóloga Blanca Guilhermina Rojas, que assumiu a subcoordenação após a desvinculação de Lúcia Helena em julho de 1986. O PMI contou com a participação de estudantes dos cursos de Ciências Sociais e História da UFPR e esteve em atividade por aproximadamente quatro anos, até o final de 1989. Os materiais produzidos pelo PMI, doados em julho de 1985 por Maria Lígia ao Museu de Arqueologia e Etnologia da UFPR (MAE-UFPR), foram divididos em materiais sonoros e textuais, e foram armazenados no Acervo Memória Indígena localizado na Unidade de Documentação Sonora e Visual (UNIDOV) do Museu.

Com o objetivo de servir de subsídio ao PMI e possíveis interessados, foram realizados levantamentos de referências bibliográficas-documentais sobre os grupos indígenas do Paraná (Guarani, Kaingang e Xetá), a partir do século XVI até 1989. Para 
tanto, foram buscados em diversas instituições relatos de viajantes, cronistas, historiadores, além de relatórios, ofícios, requerimentos, mapas históricos, legislações, jornais.

Esses materiais estão presentes atualmente em duas caixas intituladas de o1 e 02, dez pastas intituladas de o1 a 10, e uma ficha-arquivo, esta formada por um compilado de fichas de leituras que apresentam informações de 78 publicações bibliográficas relacionadas aos indígenas do Paraná e à ocupação do território paranaense. Identificada a ausência da documentação e literatura Xetá no Acervo, o escopo do trabalho que gerou esse artigo (ZILLI, 2018) emerge da leitura atenta dos projetos e relatórios produzidos pelas pesquisadoras do PMI.Concomitantemente às pesquisas bibliográfica-documentais, foram realizadas pesquisas de campo em Terras Indígenas ${ }^{3}$ distribuídas ao longo do estado em busca de narrativas produzidas pelos indígenas que pudessem se contrapor a literatura, de cunho marcadamente etnocêntrico, que vinha sendo produzida na época. O acervo sonoro é composto por um total de 148 fitas cassetes, as quais, no âmbito desta pesquisa (ZILLI, 2018), passaram por uma processo de triagem, resultando em 24 fitas cassetes produzidas sobre e com os Xetá. Este material sonoro, que possui cerca de 18 horas de gravação no total, apresenta-nos entrevistas realizadas com Ã, Tuca, Kuein e Tiqüein, pessoas pertentencentes ao povo Xetá, além de entrevistas com Dival de Souza e Domingas Rosa, ambos funcionários do SPI/FUNAI, Benedito Passenti, agricultor que residia na região da Serra dos Dourados, Antônio Lustosa de Freitas, Carolina de Freitas e Cleuraci Aparecida de Freitas - pai, mãe e filha -, os três moradores da Fazenda Santa Rosa, que será apresentada posteriormente.

\footnotetext{
3 Pretendiam-se viagens às reservas delimitadas pelo Estado sob a tutela da Fundação Nacional do Índio. Em uma primeira etapa, passariam pelos postos localizados na região centro e oeste do estado, estes seriam o PI Guarapuava, PI Rio das Cobras, PI Mangueirinha e PI Palmas, em um segundo momento, percorreriam os postos do Norte e os do Centro, por sua vez, o PI Apucarana, PI Pinhalzinho, PI Barão de Antonina, PI Queimadas, PI Ivaí, PI Faxinal e PI Laranjinha. A maioria dos antigos Postos Indígenas (PIs), atualmente conhecidos como Terras Indígenas (TIs), possuem hoje o mesmo nome. Com exceção do PI Barão de Antonia, conhecido hoje como TI Barão de Antonina I; o PI Laranjinha que chamado hoje de TI Yvyporã Laranjinha; o PI Guarapuava, por vezes referido como PI Marrecas dos Índios e hoje conhecido como TI Marrecas. A partir da verificação dos relatórios e entrevistas presentes no Acervo Memória Indígena, notou-se referência a apenas uma parte da primeira etapa do planejamento inicial, isto é, às viagens realizadas ao PI Guarapuava, Rio das Cobras e Mangueirinha. Posteriormente foram realizadas viagens a Douradina e Londrina, entretanto essas cidades só apareceram como relevantes a partir de um maior engajamento na pesquisa sobre os Xetá.
} 
O projeto do PMI escrito em 1985 informa que em grande parte dos trabalhos que vinham sendo produzidos na época, os contatos entre indígenas e não-indígenas eram examinados "a partir da ótica colonizadora da sociedade dominante" (PROJETO, 1985a, p.2) que imperava face às perspectivas ameríndias. "Fundada no modelo homogêneo e universalizante da chamada sociedade nacional" (op. cit.), essa literatura apresentava os povos indígenas ora pela ausência, "deixavam de existir enquanto grupo ‘culturalmente' diferenciado da sociedade nacional” (op. cit.), ora eram aludidos em sua expressão genérica, "como categoria abstrata e culturalmente homogênea” (op. cit.).

Em uma sociedade que possui os documentos (ou seja, registros físicos) como atestados de uma história (LE GOFF, 2003), a tentativa do PMI era de possibilitar aos indígenas que se inserissem nessa história, que até então os ignorava. As bases teóricas desenvolvidas pelos paradigmas do contato mesclava trabalhos de Eduardo Galvão, Darcy Ribeiro e Roberto Cardoso de Oliveira, autores que serviram como suporte para as abordagens propostas pelo PMI. Entre os três, sobretudo os escritos de Cardoso de Oliveira alicerçava o projeto, certamente em virtude de que Maria Lygia de Moura Pires, a coordenadora do PMI, antes fora orientada pelo autor em sua dissertação de mestrado, defendida na UnB.

O fato de terem recorrido às categorias de Eduardo Galvão e Darcy Ribeiro concomitantemente, demonstra-nos escolhas teórico-metodológicas que orientavam a equipe do PMI. Galvão (1979) propôs a existência da área IX. Paraná concernente aos Guarani Ñandeva, Kaiowá e Mbyá, e da área X. Tietê-Uruguai pertencente aos Kaingang e Xokleng, estes espaços representariam uma uniformidade cultural resultante de um ambiente modificado por uma mesma face da sociedade nacional. Assim foi possível dotar todos os diferentes grupos Kaingang e Guarani, distribuídos nos diferentes postos indígenas, de um mesmo grau de interação e dependência, e, portanto, de uma mesma narrativa englobante.

Segundo o Projeto de 1985, os Xetá, por sua vez:

Constituíam um povo pertencente ao tronco linguístico Tupi (...). Num salto de poucos anos, num período de menos de duas décadas, a partir de 1950, foram exterminados (...). Hoje restam cincos sobreviventes, sediados nos 
postos indígenas Kaingang e Guarani. Apesar de não pertencerem mais a um povo culturalmente tribalizado, pretende-se incluí-los no âmbito da pesquisa, apenas na tentativa de resgatar a memória sobrevivente Xetá - o testemunho vivo da extinção de um povo (PROJETO, 1985?, p.17).

Diferente dos outros dois povos tratados pelo PMI, a alusão aos Xetá nas áreas culturais de Galvão (1973) é nula. Este povo teria sido excluído tanto do exercício analítico por ele proposto, quanto dos mapas elaborados. Interessante constatar: um ano antes da apresentação de Galvão de suas áreas culturais, na IV Reunião Brasileira de Antropologia em Curitiba, José Loureiro Fernandes, ocupante da cátedra de Antropologia da UFPR, expôs sua comunicação intitulada Os Índios da Serra dos Dourados (1959), na qual é pronunciada a existência dos Xetá, um grupo indígena "recém descoberto no Estado do Paraná" (FERNANDES, 1959, p.27). Este povo indígena esteve na década de 1950 em "contato" com as frentes de colonização agrícolas que usurparam seu território para transformá-lo em plantações de café. Em 1956, intelectuais ligados ao Museu Paranaense, entre eles Loureiro Fernandes, já escreviam ao governador da época, Moysés Lupion, posicionando-se contra os esbulhos de terras Xetá por ele impulsionados (LIMA; PACHECO, 2017).

Interessante, pois, a história dos Xetá nos lembra a definição de Darcy Ribeiro dos povos presentes nas áreas das fronteiras agrícolas: a expansão agrícola nas últimas faixas de Floresta Atlântica, abarcou as "tribos que conseguiram sobrevier isoladas em faixas de mata" e "mantiveram-se hostis até o primeiro quartel do século (...), à medida em que se opunham à invasão de seus territórios, eram exterminados (...) uma vez que o invasor não se preocupava em poupar vidas para o trabalho escravo, mas simplesmente de desocupar a terra a fim de utilizá-la nas grandes plantações.” (RIBEIRO, 1970, p.247). Se lembramos que o que impulsionou a criação das áreas culturais por Galvão (1973) foram as diferentes frentes de expansão de Ribeiro (1970), parece-nos sem fundamento a ausência Xetá no livro Encontro de Sociedade (GALVÃO, 1973).

Darcy Ribeiro (1970), por sua vez categorizou os Xetá (ou, os Aré), quanto à situação de interação e dependência com a sociedade nacional em 1900, como índios isolados e, no ano de 1957, eles se encontrariam junto aos povos indígena que estariam na situação de contato intermitente (um total de 23 povos) (RIBEIRO, 1970). A 
referência de Ribeiro aos Xetá é rápida, resume-se à sua menção nas tabelas à inclusão deles no Índice de tribos presentes no mapa da "área cultural IX. Paraná" (RIBEIRO, 1970, p.469).

Empregando os termos de Darcy Ribeiro, os Xetá não se apresentavam mais a nenhuma categoria dos anos anteriores. O PMI aponta a mudança de sua categoria: foram extintos. De 1959 a 1985 (pós Índios e a civilização de Ribeiro, e o ano de início do PMI) a "tecnologia do contato e das remoções" (LIMA; PACHECO, 2017) se intensificou e os Xetá, nos termos do PMI, deixaram de "se reproduzir e desenvolver de forma harmônica". (ÍNDIOS, 1987, p.3). De "últimos redutos de povos caçadorescoletores da América Meridional” (PROJETO, 1985?, p.17), o extermínio do povo Xetá dotou seus sobreviventes, segundo o PMI, da posição contraditória de "o testemunho vivo da extinção de um povo" (ÍNDIOS, 1987, p.3).

É preciso que reste bastante claro que as realizadoras do PMI não eram exceção ao estabelecer esse diagnóstico da "extinção" dos Xetá. Como escreveram recentemente Lima e Pacheco (2018), os Xetá foram totalmente ocultados na literatura etnológica sul-americana, sob a rubrica de "extintos". Isso alcançava tanto as obras de Darcy Ribeiro quanto de outros pesquisadores que os conhecia proximamente, como era o caso de Loureiro Fernandes, que escreveu sem rodeios em um periódico internacional: "Seguramente é um desafio urgente para a antropologia estudar esse pequeno grupo de pessoas que, devido à sua forma primitiva de viver, estão fadados a morrer no futuro próximo". Dada a força de suas palavras, não nos parece exagerado observar que o artigo se assemelha a um obituário precoce.

Voltando ao PMI, apresentada a "descaracterização cultural" (PROJETO, 1985b, p.2) e a impossibilidade da continuidade da cultura "tribal", todas as características sociais e culturais dos Xetá foram referidas ao passado, aos sobreviventes deste tempo teria restado apenas a vida "destribalizada" e a memória de uma cultura e sociedade que não existe mais.

Os Xetá, em um certo momento, deslocaram-se de uma posição acessória dentro do PMI para integrantes um subprojeto intitulado Pesquisa Xetá. Não foi possível identificar a data exata dessa mudança de posição, entretanto, em relatório referente a agosto e setembro de 1988, foi mencionada uma viagem realizada 
novamente ao PI Guarapuava, de quatro a dez de setembro de 1988, com a finalidade de complementar a pesquisa sobre Xetá. Nesse mesmo relatório, apresenta-se o início das transcrições referentes às entrevistas realizadas com esse povo e o estabelecimento de "vários contatos no intuito de reunir todo o material existente a respeito dos Xetá" (ROJAS, 1988. p.2). Sobre essa última atividade, os pesquisadores percorreram diferentes instituições que poderiam fornecer informações bibliográficas-documentais: o Museu de Paranaguá (atual Museu de Arqueologia e Etnografia/UFPR), o Centro de Estudos Bandeirantes, localizado em Curitiba, e o Museu do Índio, localizado no Rio de Janeiro.

Contudo, apesar do maior engajamento que resultou em uma mudança no tratamento da presença da chamada "história Xetá", o PMI continuou referindo-se ao grupo como um "povo extinto”. Em relatório encaminhado à agência financiadora do PMI, o CNPq, em abril de 1989 voltaram a escrever:

\footnotetext{
Diante da existência de poucos membros sobreviventes do grupo Xetá (povo extinto na década de 50), não se constituindo em grupo ou cultura tribal. Elaborou-se este sub-projeto [Pesquisa Xetá], onde a pesquisa está recolhendo depoimentos dos remanescentes e levantando artigos científicos, anotações pessoais, correspondências que a eles se referem, com objetivo de recompor a história desse povo (PIRES; WAWRZYNIAK, 1989, p.1).
}

Engajaram-se no armazenamento da memória Xetá com dois fins: guardar aquilo que foi perdido, pois houve a extinção, mas também denunciar o projeto colonial a qual foram submetidos a partir de suas vozes. Foi verificado nos relatórios, a busca por outros sobreviventes, como Thiara, um mulher xetá que cumpriu pena por assassinato no presídio feminino de Piraquara, além do acompanhamento do processo judicial movido contra Tikuein (PIRES; ROJAS, 1987?). Nas entrevistas, os pesquisadores buscaram em Ã, Kuein, Tuca e Tiqüein os detalhes e particularidades de suas vidas.

Apesar de terem, nas palavras dos pesquisadores, "perdido muito de suas características culturais" (ÍNDIOS, 1987, p.5), os Xetá (e os Guarani e Kaingang) “ainda se consideram - e são considerados pelos demais - como índios.” (ÍNDIOS, 1987, p.5). Para entenderem a identidade étnica, os pesquisadores do PMI recorreram à abordagem de Roberto Cardoso de Oliveira. A identidade étnica emergiria e se 
configuraria como ideologia a partir da relação e oposição entre os povos indígenas, e sua "ordem tribal”, e a "ordem nacional". Estas identidades não seriam mais que a autorepresentação de um outro espelhado no indivíduo “subjugado”.

Por mais que a categoria extinção continue sendo utilizada, há um certo otimismo quanto ao "fim" do povo Xetá. Ainda que tivessem tomado a extinção como ponto de partida, o fim não estaria em completo acordo, engajaram-se no reconhecimento do povo Xetá independente do seu fim.

\section{Narrativas em disputa}

Conformam-se, no passado fragmentado, visões distintas sobre os eventos em torno do contato dos Xetá4. Por um lado, portanto, buscaremos alcançar quais eram as categorias mobilizadas que serviam como legitimação aos atos dos interlocutores nãoindígenas; por outro, quais categorias e mobilizações estavam sendo articuladas pelos interlocutores Xetá que viriam desembocar no “ressurgimento étnico” Xetá (LEITE, 2017) na década de 1990, quando os sobreviventes e seus descendentes delinearam um cenário de reinvindicações públicas ao Estado em busca de medidas reparatórias e reconhecimento étnico.

O relatório da Comissão Nacional da Verdade (2014) apresentou que o estado do Paraná, sob o mandato de Moysés Lupion, doou no ano de 19511.400 (mil e quatrocentos) alqueires de terra à Antônio Lustosa de Oliveira, ex-deputado estadual e amigo de Lupion. Além da doação de terras visando fortalecer a hegemonia políticopartidária, o noroeste do Paraná despertava o interesse de grupos econômicos que lotearam e venderam as terras da região com o aval do Estado do Paraná. No ano de 1949, lembrado por um dos entrevistados não-indígenas como o ano de "maior esbulho de terras do Paraná" (DIVAL, 1986: Fita 109), o Governo do Estado, já ocupado por Lupion, fez um acordo com o Governo Federal, diminuindo as áreas indígenas e destinando suas porcentagens "excedentes" à companhia colonizadora Suemitsu

\footnotetext{
${ }^{4}$ No processo de pesquisa do acervo Memória Indígena, localizado no Museu de Arqueologia e Etnologia da Universidade Federal do Paraná (MAE-UFPR), foram levantadas o total de 11 (onze) fitas cassetes contendo gravações com os Xetá, e 13 (treze) fitas cassetes cujo conteúdo eram entrevistas com não-indígenas que tiveram contato com eles (ZILLI, 2018).
} 
Miyamura \& Cia. Ltda, esta que viria ser substituída em 1951 pela Companhia Brasileira de Imigração e Colonização.

O reconhecimento dos Xetá no noroeste do Paraná justificava ao SPI a necessidade de um Posto de Atração na região, para tanto a fazenda Santa Rosa (localizada em terras doadas a Antônio Lustosa de Oliveira) passou a servir a esse fim. A ideia de atração revestia as técnicas do órgão indigenista voltadas tanto aos índios arredios que vinham "sistematicamente evitando relações com a administração, quanto os que, apontando em termos geográficos, não mantêm contato sequenciado nem o negam” (SOUZA LIMA, 1995, p. 179). Assim, a mando de Deocleciano de Souza Nenê, chefe local do SPI, foram construídas casas no entorno da fazenda para servir aos funcionários do órgão estatal, a fim de atraírem pacificamente os indígenas a estes locais - embora não seja demais lembrar que o contrato efetivo foi estabelecido pelo sobrinho do proprietário, Antônio Lustosa de Freitas, que, acompanhado de sua esposa, Carolina de Freitas, fazia à época o papel de caseiro e capataz na fazenda mencionada.

Os Postos de Atração do SPI foram criados sob justificativa de uma política tutelar de amparo a esses povos considerados vulneráveis. Entretanto, à medida em que os indígenas eram atraídos, seus territórios ficavam vazios e disponíveis aos interesses privados das empresas colonizadoras. Segundo Pacheco de Oliveira, "a atuação tutelar e pacificadora do SPI levou ao vertiginoso aumento do valor da terra em todas as regiões em que o órgão assim atuou". (PACHECO DE OLIVEIRA, 2014, p.137). O mesmo se repetiu no noroeste paranaense.

Os mecanismos do SPI de aniquilação da diferença operados através da tutela, não escaparam aos Xetá. Vivendo em liberdade, esse povo representava um obstáculo ao desejado progresso, i.e. à entrada da colonização em suas terras. Assim, em meados do século anterior, o governo do Paraná e as companhias colonizadoras promoviam ações para transformar a retórica do vazio demográfio em situação de fato (LIMA; PACHECO, 2017).

A chegada dos invasores não-indígenas, não foi recebida exatamente como uma novidade, uma vez que antes já havia sido anunciada por Kóguay a seu filho. Kuein - o mais velho Xetá ainda vivo e morando na Terra Indígena Marrecas, nas 
proximidades de Guarapuava - apresenta em suas falas que, quando criancinha, ficava todas as noites deitado com seu pai, ouvindo as histórias que ele tinha para contar. Em uma dessas histórias, Kóguay contou a seu filho a respeito da existência dos brancos e a chegada deles:

K: Ele [meu pai] tá contando pra você "tem branco por aí, um monte de branco por aí" (...) "mas logo o branco vai aparecer" (...) Disse pra mim: "Eu tô com medo dele", "quando te pegar você não vai corre dele, você fica com ele depois quando chegar de noite a gente te cata, uma hora da noite a gente te cata”, ele disse pra mim, (...) contou que tinha espingarda, tinha arma, né? Tinha espingarda, tinha foice de cobre, foice, tinha, como é que é, roupa, tinha chapéu de pano, tinha timboca, tinha sapato, tinha chinelo de dedo, mas meu pai ta contado tudo, mas eu nunca vi $[. .$.$] o homem [...] tá preparando terra$ $[\ldots]$ com foice [...] e agora vai tomar terra. E tomou memo.

E: Tomou.

K: Tomou memo.

E: Teu pai tava certo.

K: Meu pai tá certo que ele contou pra mim (KUEIN; ENTREVISTADORA, 1986: Fita 111).

Esse ser branco, que toma as terras indígenas, aparece nas narrativas de Kuein, Tuca e Tikuein (SILVA, 2003), utilizando roupas, elementos diacríticos que exprimem uma outra categoria de pessoa. No evento do rapto de seu pai pelos brancos, esses elementos foram novamente recuperados por Kuein. As vestimentas, botas, chinelos, chapéus, calças, cintos, juntos com suas ferramentas, a foice, a espingarda, a arma, o telefone, a timboca, caracterizam o kikãdjy desde as histórias de um tempo 'muito antigo' até o momento da narrativa de Kuein.

E: Pois é, aquele dia o senhor já me contou um pouco, né? Você me falava quando você morava lá com sua gente...

K: É, morava lá no mato. Minha mãe morreu primeiro, depois meu pai morreu. Meu irmão mais novo morreu...

E: Como ele se chamava?

$\mathrm{K}$ : $\mathrm{O}$ mais velho ele veio aqui, morreu aqui. $\mathrm{O}$ outro mais novo morreu lá no mato mesmo (KUEIN; ENTREVISTADORA, 1986: Fita 111).

Incentivado a discorrer sobre sua vida no mato, as primeiras lembranças recuperadas pela memória e evocadas na fala de Kuein são sobre a morte de seus parentes. Kóguay, seu pai, morreu doente, “com fome” e "em pé dentro da toca de madeira, [...] galho, madeira bem grande” (KUEIN, 1987: Fita 84), “quando bem na hora 
que meu pai morreu, os brancos chegaram" (KUEIN, 1986: Fita 111). A morte de sua mãe também foi provocada por uma doença, única referência e explicação de Kuein à morte de Patayo.

As mortes e doenças relacionadas ao mato, categoria nativa utilizada igualmente pelos outros interlocutores Xetá ao se referirem aos seus territórios de origem, foram constantemente evocadas em suas falas. As carnes que não existiam na Serra dos Dourados em conjunto com o sal, em oposição à anta, ao cateto, ao porco do mato, levavam a morte.

A essa carne salgada produtora da doença, geradora da morte, era vetada, "não podia comer" e aos brancos era associada sua aparição. O sal, entretanto, não era vetado apenas por sua associação ao branco, no trecho anterior Kuein contou que esteve junto a um homem branco que deu a ele carne com sal, que foi recusada. Entretanto, deu também o café e o arroz doce, que foi aceito e apreciado, indicando uma seleção de substâncias 'brancas’ autorizadas a serem ingeridas.

Os kikãdjy portadores de roupa, além de possuírem o sal, apropriarem-se de seus territórios e os violentarem, roubavam os indígenas. Os raptos não somente foram mencionados repetidamente nas falas de Kuein e dos outros Xetá, mas também delinearam muitas trajetórias. Em alguns casos, como o de Kóguay, a resistência era articulada para que a pessoa raptada voltasse a seus parentes; outras vezes, contudo, ainda que resistissem, o rapto se efetivava.

Kaiuá, irmão da entrevistada Xetá chamada Ã, foi raptado pelos agrimensores: “cercaram ele e o apunharam, daí levaram ele para o acampamento, aí avisaram e fomos [o SPI] lá buscar” (DIVAL, 1989: Fita 89). Alguns meses depois, Dival contou, na entrevista, que encontraram Tuca "trepado" em uma árvore, os agrimensores que o

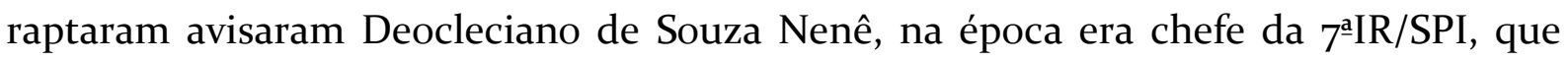
“voltou e levou Tuca, em novembro de 1952, quase 1953” (ANTÔNIO, 1989: 119).

Geraldo, outra criança, foi pego deliberadamente por Antônio Lustosa de Freitas, sobrinho do dono da Fazenda e um dos entrevistados pelo PMI, que possuía a justificativa da "fartura" de alimentos que poderia oferecer à criança que, segundo ele, vivia em privação. O Mã [pai de Geraldo] "tinha medo de gado, mas ele ficava na porta. Quando foi um belo dia, ele deu um bote, o indiozinho escapou e então peguei um 
pedaço de pau de bater em vaca e ameacei nele, mas só ameacei pra... mas daquele dia em diante ele nunca mais procurou pegar o menino" (ANTÔNIO, 1989: Fita 126).

Vivendo com os não-indígenas, Geraldo passou a servir como mediador entre os brancos e seu povo. Antônio Lustosa contou às entrevistadoras que a criança conversava com seu pai que, por sua vez, repassava as mensagens ao Adjakutã. Seria Geraldo uma "fonte de informações” do mundo dos brancos aos Xetá? O que sabemos, é que a justificativa humanitária aparece como motor das ações de Antônio Lustosa:

\footnotetext{
A: A indiazinha que eu crio, a indiazinha, a Tiguá, que era bem, eram primos, bem menor que o finado Geraldo, então eu digo, eu vou fazer uma caridade, ela vai morrer essa então eu vou [sepultar (?)], era o couro em cima dos ossos (...) se você visse ela desse tamainho os ossinhos eram do tamanho do meu dedo, era só couro em cima dos ossos, era dilatada a barriga, parecia grávida, nem umbigo tinha de tão que era crescido. (...)

A: Ela [outra menina indígena, conhecida por Tiguazinha]... eu que tirei dos pais e dei pra minha filha.

E: Sim, mas tinha algum motivo?

A: Não, nada... (...) Naquela época, se eu tivesse condições eu criaria todos os pobrezinhos. Tinha que ver o sofrimento deles que não era brincadeira não (ANTÔNIO, 1989: Fita 128).
}

Ã, irmã de Kaiuá, também foi uma das crianças retiradas do noroeste do Paraná e levada para Curitiba. Cumprindo ordens de Dival, filho de Deocleciano de Souza Nenê e também funcionário do SPI, Ã foi levada por um funcionário do SPI chamado Alan Kardec ao PI Apucaraninha, local que passou a viver com esse chefe de posto e sua família, e contou:

E: Ela tá, mas ela já, vocês já tinham visto branco?

Â: Aham, eu já.

E: Já...

Ã: Daí eu... Eu era pequena, não sabia, vivi na mão do Dival, não conheci minha mãe nem meu pai, vivi na mão dos outros (Ã; ENTREVISTADORA, 1986: Fita 110).

Esse momento de saída do mato, "na mão do Dival”, foi registrado pelo Vladímir Kozák, fotógrafo e etnógrafo que acompanhou algumas expedições de contato. Na fotografia abaixo, Dival encontra-se puxando o burro de carga no qual Ã é transportada: 
Figura 1 - Ã sendo levada por Dival

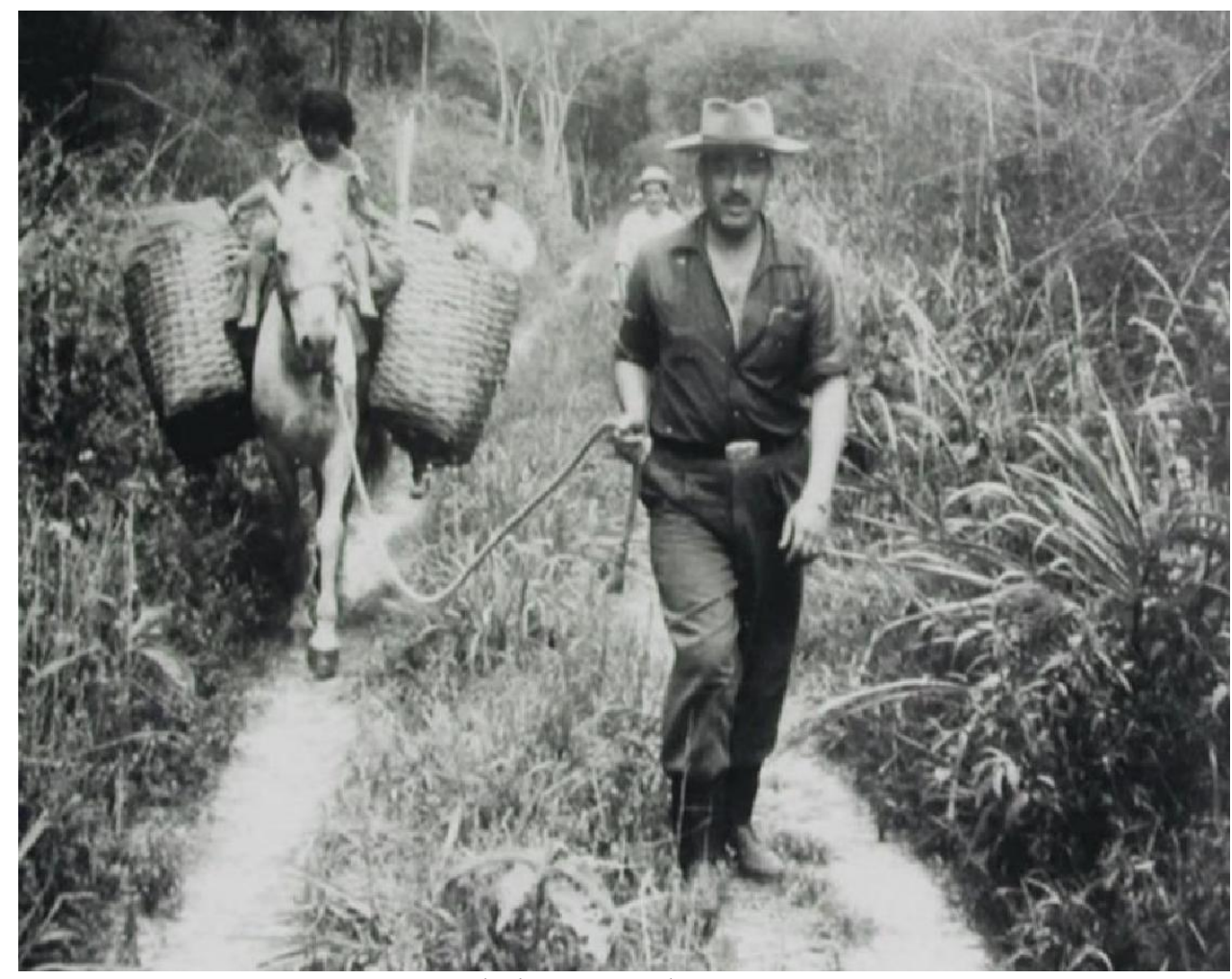

Fonte: Vladimír Kozák. Acervo MAE.

Geraldo, Tuca, Kaiuá, Tiguá, Tiguazinha e Ã não foram as únicas crianças raptadas, Antônio fala do rapto como sendo uma prática comum entre os brancos, indica a existência de mais crianças retiradas:

A: (...) e aquela que o Mã queria que é... É... A que tinha mais lida, tinha mais lida... É... não era essa que ficou com o Arigã [Eirakã], ele tinha mais lida com a verdadeira mulher dele, que era a mãe do menino que o Joaquim levou para Belém do Pará (ANTÔNIO, 1989: Fita 119).

Em outros trabalhos de pesquisa consta também o caso do menino Xetá conhecido como Natal, que criado por frei Estevão, em Umuarama, mas que na maioridade saiu de seus cuidados e dele não se tem mais quaisquer informações, podendo mesmo estar vivo.

Os raptos e dispersões liberavam a terra ao mesmo tempo que possuíam a tarefa de disciplinar os corpos indígenas em acordo com a "política paternalista" então vigente no SPI, instituição em que Dival trabalhava. De sua perspectiva, o SPI estaria francamente a favor dos povos indígenas, visto que seu objetivo era garantir uma vida 
melhor a todos, muito especialmente aos indígenas recém-contatados, como Xetá. Seu papel como tutor desses povos seria, em sua concepção, o de ser um "um pai enérgico" (DIVAL, 1986: Fita 113), cujo poder disciplinar autoritário faria os indígenas "trabalharem forçado" (DIVAL, 1986: Fita 112), casoe isso fosse necessário para que não passassem fome. Mas, para além de um "humanitarismo", as narrativas de Dival aludem ao "exercício de uma disciplina orientadora do comportamento sociocultural" (BRINGMANN, 2015, p.25) que operam como tecnologias de integração e aniquilação daquilo que difere os não-indígenas dos indígenas (FOUCAULT, 2006).

As falas sobre as crianças que eram raptadas por agrimensores de terra, entregues ao SPI e levadas para longe de seu povo começam a apresentar a condição de precariedade as quais as vidas Xetá foram posicionadas. Vidas precárias, "politicamente construídas através da qual determinadas populações são assimetricamente expostas a contextos de violência, perigo, enfermidade, migração forçada, pobreza ou morte" (BUTLER, 2015, p.25).

Como os quadros de guerra descritos por Butler (2015), as vidas Xetá eram posicionadas como vidas não passíveis de luto:

\footnotetext{
Uma vida específica não pode ser considerada lesada ou perdida se não for primeiro considerada viva. Se certas vidas não são qualificadas como vidas ou se, desde o começo, não são concebíveis como vidas de acordo com certos enquadramentos epistemológicos, então essas vidas nunca serão vividas nem perdidas no sentido pleno dessas palavras (BUTLER, 2015, p.13).
}

Vidas precárias (op. cit., 2015), vidas que foram desumanizadas pois fugiam de enquadramentos normativos que estabelecem quais vidas devem ser preservadas ou lamentadas, quais são dignas de ser vividas.

Retirado de seu povo, Tuca também desempenhava múltiplas funções após ser retirado de perto de seus parentes: servia aos brancos, seja como intérprete, seja como trabalhador na pensão da família do Dival:

E: O que você fazia lá?

T: Trabaiá, né? servia mesa, lava louça...

E: Na casa de alguém que você trabalhava?

T: Lá na pensão mesmo, né? Que eu me criei.

E: Ah... Uhum. 
T: Lá na pensão do [Deocleciano] Nenê de Souza... Na [rua] Sete de Setembro, bem na frente com a escola técnica ali, né?

E: Ah, sei, com a [rua Desembargador] Westphalen,, né?

$\mathrm{T}$ : É, bem na esquina, pensão [...].

E2: Você que tomava conta [...]?

T: Era seu Dival, né?

E2: Seu Dival?

T: E a mãe dele que [começou(?)] a ensinar, a ensinar a fazer as coisas [...] fui aprendendo (TUCA; ENTREVISTADORA, 1987: 121).

Sem justificativa "humanitária", os Xetá passaram a servir como trabalhadores aos não-indígenas. De corpos que antes eram somente precários, passaram também à condição de corpos úteis quando esparramados, conforme fica também claro na fala de Á:

Ã: Eu limpava, arrumava a cama, enxaguava [...].

E: O que?

Ã: Passava roupa.

E: Ah, é? Ele tinha filhos?

Ã: Tinha só um.

E: Só um menino?

Ã: Um piá. Desse tamanhozinho aí, bem alto.

E: Ah... Ele já era grande.

Ã: Uhum, agora ele tá grande já.

$\mathrm{E}: \mathrm{Ah}$, mas ele era mais ou menos da sua idade?

Â: Uhum.

E: E você brincava com ele?

Ã: Não, eu tinha que cuidar, eu era babá dele.

E: Ah, a senhora era babá dele;

Ã: Uhum. (...)

E: E você cresceu lá naquele posto lá?

Ã: Em Apucarninha que eu cresci (命; ENTREVISTADORA, 1986: Fita 110).

Independente de seus papéis e posições na sociedade nacional, os interlocutores brancos do PMI podem ser pensados como "modernos disciplinadores dos índios brasileiros" (VIVEIROS DE CASTRO, 2002, p.129). Seus discursos sobre os Xetá são permeados por concepções civilizatórias que dotam o indígena da necessidade de tutela como meio de normatização dos povos indígenas.

E(o): Como que foi o processo de extinção deles, senhor Dival?

D: Naturalmente...

E(o): Foi acabando...

D: Foi tento contato, dando [...] desapareceu aos poucos, os únicos que se salvaram foram esses que trouxemos.

$\mathrm{E}(\mathrm{o})$ : Na região mesmo,, né? 
D: É... Só eles [...].

(...)

D: [...] existiam na mata, descobriram com o contato, foi uma coisa natural... Depois de lá quando apareceu a [...] daí ficaram prensados entre o rio Paraná e nóis aqui, né? [...].

E1: Mas talvez na hora que depois que viesse a descoberta pro povo, um certo... Eu acho que daí talvez tenha sido pior, né?

D: É... Olha, foi uma luta tremenda (DIVAL, 1986: Fita 109).

A extinção não foi vista como fato consumado apenas por parte dos próprios pesquisadores do $\mathrm{PMI}$, mas também pelos entrevistados não-indígenas. E para além disso, os Xetá aparecem na fala de Dival como integrantes da mata, dizimados pois a própria natureza era destruída no processo colonizador. Nessa concepção, ser da natureza os dotava de uma condição de "selvagens" cuja cultura, local do "civilizado", serviria para domá-los e civilizá-los, fazendo deles um igual.

E: Eles não tiveram contato assim agora depois de grande contato com os [...] não?

DR: Não, eu acho que..

D: Perderam tudo.

DR: Perderam tudo, tão é...

E: Como é que a senhora explica assim já que perderam tudo que o Rondon continue vivendo em uma área indigena, né? E casar com índia enquanto que o Tiqüein não quer viver na area indigena e casou com branca.

DR: Pois aí é a ideia de cada um deles, né? (...).

DR: Quiseram casar \{risada\} mas eles tavam feliz, muito feliz. Ela era boazinha, muito caprichosa. Mas a índia é mestiça seu Dival, né?

E: É Kaingang ou...

DR: É Kaingang, porque Xetá não tem mais meios para continuar a raça pura, né?

D: Não tem. Porque por exemplo a Iati eu sei que é índia pura, mas é a índia pura mestiça, Xetá com Guarani, né? Ela não é só xetá, né? A minha esposa viu Dona Rosa, eu nunca disse nada para a senhora [...] Rondon, e ela sempre pensava que o [...] mas ela tinha esperança de ver que o Rondon casava com a Nhatxê [Aruay] \{risada\} (DONA ROSA, DIVAL, ENTREVISTADORA, 1988: Fita 117).

Nesse prisma de "incorporação" de costumes da população “civilizada”, os indígenas perderiam sua essência e se descaracterizariam. Mas antes, segundos os interlocutores não-indígenas, ser Xetá e ser passível de descaracterização é ter o sangue "puro" da etnia. A partir dessa valorização da "pureza racial”, a miscigenação era vista como “degeneração” que viria enquanto ameaça à etnia Xetá. 
Há no discurso não-indígena um ideal de pureza como meio de continuidade da "raça" compartilhado por aqueles fazendeiros, como é a caso de Cleura, filha de Antonio Lustosa de Freitas (CLEURA, 1989: Fita 127):

\begin{abstract}
$\mathrm{Cl}$ : Porque infelizmente cê sabe né? Do jeito que tá, só resta o passado e a lembrança.

C: Você sabe que em Londrina ainda tem um pessoal que se preocupa e eles tem uma esperança de conseguir ainda um lugar pra esse pessoal pensando que eles poderiam ainda se juntar e viver juntos.

Cl: Eu por exemplo no meu pensamento, o que eu acho, é que essa tribo não deveria ser extinta. Deveria ainda haver casamento entre eles mesmo pra ficar os Xetás verdadeiros, né? Do jeito que eu tô vendo, por exemplo, o da Tiguá já é mestiço, já é com branco. Daqui a pouco essa tribo já não é mais a tribo dos Xetás (CLEURA; CAROLINA, 1989: Fita 127).
\end{abstract}

O fim do sangue Xetá e, consequentemente, o fim dos Xetá "verdadeiro", trariam a extinção pois a "pureza" se esvairia. Nesse cenário, segundo os não-indígenas, restaria somente uma saída como salvação, os "remanescentes puros" casarem-se entre si. Mesmo sendo conhecedores da genealogia das famílias Xetá em que estiveram em contato (Antônio, Fita 128 e Fita 126), os moradores da fazenda Santa Rosa pensavam os Xetá como passíveis de serem “cruzados como bichos” (CLAUDEMIR DA SILVA, 2018) 5 .

Vivendo em Curitiba por aproximadamente 20 anos, Tuca, entrevistado Xetá, contou que sempre viajava com o José Loureiro Fernandes para Serra dos Dourados. Segundo Tuca, Loureiro era um médico que "estudava” na língua, "ele me levava muito" (TUCA, 1987: Fita 121). Em companhia deles, Tuca conta que ia também Kózak, então funcionário da atual UFPR, era ele o "homem que filmava”. A José Loureiro, Tuca contava as coisas, ensinava a "nossa língua" (TUCA, 1987: Fita 121), nunca aprendeu a escrever em português, suas histórias eram registradas por pesquisadores que escutavam o que ele dizia e "escreviam”.

Os brancos, pensados enquanto uma categoria de pessoa que tem suas diferenças inscritas no corpo e em suas atitudes, podem ser acessados pelos Xetá quando adquirem códigos não comuns a eles como a utilização de roupa, o

${ }^{5}$ Como se expressou Claudemir da Silva, filho de Tikuein, um dos sobreviventes Xetá, no evento Os Xetá e seus acervos: história, antropologia e memória, realizado no Círculo de Estudos Bandeirantes, Curitiba/PR, nos dias 13 e 14 de junho de 2018. 
compartilhar de certas comidas, quando aprendem a trabalhar e a desempenhar tarefas tipicamente brancas, quando se casam com brancos.

Podemos entender o "aprender" como o captar da experiência branca, ser capaz de fazer coisas que os brancos fazem, uma vez que em diferentes trechos a palavra "aprender" aparece articulada com ações desempenhadas por pessoas brancas: o falar o português, o fazer os serviços de casa, limpar, cozinhar, passar

A incorporação de rituais e práticas que eram em um passado atribuídas a operadores externos (como as roupas, as comidas, certas noções como a ideia de "trabalho", de "aprender", de "casar com branco"), não significa que tenham deixado de ser "autenticamente" indígenas e se transformado "índios aculturados". Essa era a perspectiva dos colonizadores que os violentaram, não deles próprios, que se viam em meio a aprendizados das práticas dos brancos, mas não incorporados ou "integrados".

Mesmo dispersos, todos os interlocutores Xetá responderam o contrário à ausência da coletividade. O projeto de pulverização empreendido sobre os Xetá aparece como falho quando pensado que mesmo afastados, a coletividade ainda acontece ou é desejada, permanecendo unidos por laços de parentesco, embora estejam ocupando espaços e modos de vidas diferenciados. Apesar de não estarem juntos, os quatro interlocutores que foram ouvidos no PMI expressam em suas falas a presença dos outros Xetá em suas vidas, recusando a tese da extinção à qual as próprias realizadoras do projeto aderiam:

\footnotetext{
E: Me conta um negócio, da tua gente, a tua gente que você tava quando o branco apareceram tava toda tua gente lá ou tem mais? Tinha ficado lá ou...

$\mathrm{K}$ : Tem bastante tem outro tem outro tem bastante que morava, muito pouco que [morreu(?)] [17m39] [...] tem em Marreca, no Ivaí, também é.. Como que é [...], ta no Rio das Cobras.. Tem em Mangueirinha... Tem como que é... Palma... Tem um pouco, tudo mais [no rancho(?)] tudo no Mato Grosso [Serra dos Dourados] mais... [sete que sumiu(?)] (...) (KUEIN; ENTREVISTADORA, 1987: Fita 84).
}

Não é porque não possuem mais acesso às suas terras e estão "desprovidos de forte contrastividade cultural" (PACHECO DE OLIVEIRA, 1998 p.52), que a sociedade Xetá se encontra a caminho do extermínio e sua cultura se encontra em ruínas. Enquanto o percurso dos pesquisadores do PMI foi o de pensar os "remanescentes" 
Xetá a partir da ideia da falta (tanto da cultura, como da sociedade), os membros desse grupo étnico rumam na direção oposta, reafirmando uma unidade, ainda que diferente da anterior.

\section{Considerações finais}

A memória é formada a partir da narração e não é um mero ato de rememoração aleatório. Para Pollak (1992), as narrativas mnemônicas se fazem em uma situação de reafirmação social ou de construção de si mesmo e nada tem de espontâneo pois "uma pessoa a quem nunca ninguém perguntou quem ela é, de repente ser solicitada a relatar como foi a sua vida, tem muita dificuldade para entender esse súbito interesse" (POLLAK, 1992, p.13).

Quando a identidade é ameaçada faz-se necessário recorrer à memória e à narrativa memorial para assim afirmá-la: “A busca memorial é então considerada como uma resposta às identidades sofredoras e frágeis que permitiria apoiar um futuro incerto em um passado reconhecível" (CANDAU, 2012, p.10).

Faz-se presente nas falas dos interlocutores indígenas a ênfase e a importância das histórias contadas a eles por seus pais. Para Pollak (1992), as memórias transmitidas e herdadas são os mais importantes meios de conexão entre memória e identidade por estimularem as memórias compartilhadas, nas quais se sustentam os conhecimentos da coletividade. Assim, as narrativas apresentadas por Kuein, Ã e Tuca, ao apresentaram incessantemente uma organização e releitura do passado que remete ao parentesco, dota ele do lugar onde se encontram as bases identitárias Xetá, uma vez que as identidades pessoais encontram no grupo seus referenciais (CANDAU, 2012).

Diante disso, é inegável o posto modelador da memória em relação à identidade, afinal o que foi objeto da faculdade mnemônica, a forma como foi lembrado e o significado atribuído ao passado, no presente determinam o modo como a identidade será reconstruída, reafirmada (op. cit.). Isso é a dialética da memória e da identidade que "se conjugam, se nutrem mutuamente, se apoiam uma na outra para produzir uma trajetória de vida, uma história, um mito, uma narrativa” (op. cit., p.16). 
Rememorar, portanto, é um trabalho empreendido para visitar o passado, mas que está calcado no presente e por isso é também uma forma de revisar o agora (CANDAU, 2012). Dessa forma, narrar pode ser percebido como um trabalho de conferir outros sentidos ao passado. Esse é um ponto importante da relação entre memória e identidade que ganha forma por meio do discurso, pois, para conferir significado ao tempo vivido e às experiências dos indivíduos, é preciso escolher algumas lembranças e excluir outras.

O que emerge das vozes xetá registradas no PMI, é que seu movimento representa uma insurreição contra a invisibilidade a que estiveram submetidos. Neste sentido, cabe celebrar aqui a realização do PMI, o primeiro de vários outros que o sucederam que buscam essas vozes antes inaudíveis. Retomar os registros desse projeto permite historiar as batalhas que continuam sendo realizadas no presente dos Xetá para que seu passado seja esquecido. Da invasão de suas terras até os dias de hoje, os Xetá seguem contrariando a teoria do desalento (SAHLINS, 1997) que, no contexto do PMI, assolava os não-indígenas - sejam os entrevistados, sejam as entrevistadoras que os enxergavam enquanto um povo fadado ao extermínio e a morte.

Em contraposição, as narrativas Xetá apresentam a existência de uma coletividade, ainda que diferente da época do mato. Do contato aos dias de hoje, o que os Xetá apresentam é aquilo que Carneiro da Cunha (2009, p.234) escreve sobre identidade étnica ser algo produzido para fora, em contexto interétnico específico, operante a partir da política. Sob esta perspectiva, quem define a identificação étnica não são os antropólogos ou os não-indígenas, mas os próprios Xetá, a partir de situações sociais e históricas específicas que os alcançaram.

Seguindo esses pensamentos, e recusando-nos a falar de "perdas culturais", conseguimos entender a articulação política Xetá que veio a ser intensificada na década de 1990, produzindo a recuperação demográfica e a organização política, que permite que estejam, atualmente, aguardando a homologação de suas terras na Serra dos Dourados.

Lima (2018, p.16) mostra como os documentos etnográficos e históricos produzidos sobre os Xetá, entre a década de 1950 e 1970, vêm ganhando na atualidade, a partir deles próprios, novas significações e intenções, instruindo "processos que 
confirmam sua perseverança enquanto grupo culturalmente diferenciado e embasam suas reivindicações políticas”. De certa maneira, como se os documentos produzidos naquele período - o PMI entre eles - alcançassem propósitos inimaginados antes: se se pensava que documentavam a extinção de um povo, atestam hoje justamente o contrário, sua existência e resistência.

\section{Referências}

BENJAMIN, Walter. Sobre o conceito de História, In: Magia e técnica, arte e política: ensaios sobre literatura e história da cultura. Obras escolhidas, volume $1.3^{\underline{a}}$ ed, São Paulo: editora brasiliense, 1987.

BRINGMANN, Sandor Fernando. Entre os índios do Sul: uma análise de atuação indigenista do SPI e de suas proporsta de desenvolvimento educacional e agropecuário nos Postos Indígenas Nonoai/RS e Xepecó/SC (1941-1967). Tese (Doutorado em História) - Universidade Federal de Santa Catarina, Florianópolis, 2015.

BUTLER, Judith. Quadros de Guerra: quando a vida é passível de luto. Rio de Janeiro: Civilização Brasileira, 2015.

CANDAU, Joël. Memória e Identidade. Tradução: Maria Letícia Ferreira. São Paulo: Contexto, 2012.

CARNEIRO DA CUNHA, Manuela. Cultura com Aspas e outros ensaios. São Paulo: Cosac Naify, 2009.

CNV. Violação dos direitos humanos dos povos indígenas. In. Relatório da Comissão Nacional da Verdade. Brasília, v. 2: 197-256, 2014.

FERNANDES, José Loureiro. Os índios da Serra dos Dourados (Os Xetá). Anais da III Reunião Brasileira de Antropologia, Recife, p. 27 - 46, 1959.

. "The Xetá - the dying people in Brazil", Bulletin of the International Commitee on Urgent Anthropological Research, Vienna, n. 5, 1962. p. 151-154.

GALVÃO, Eduardo. Índios e brancos no Brasil: encontro de sociedades. Rio de Janeiro: Paz e Terra, 1979 [1973].

LE GOFF, Jacques. Documento/monumento. História e memória. $5^{\mathrm{a} e d}$. Campinas: UNICAMP, 2003. 
LEITE, Gian Carlo Teixeira. Do contato aos dias atuais: sete décadas de notícias sobre os Xetá da Serra dos Dourados. Monografia (Graduação em Ciências Sociais) - Universidade Federal do Paraná, 2017.

LIMA, Edilene Coffaci de. Exílios índios: sobre deslocamentos compulsórios no período militar (1964-1988). ACENO, Vol. 3, N. 6, p. 18-35. Ago. a Dez. 2016.

LIMA, Edilene Coffaci de; PACHECO, Rafael. Povos Indígenas e Justiça de Transição: reflexões a partir do caso Xetá. ARACÊ - Direitos Humanos em Revista, Ano 4, Número 5, Fev. 2017.

. Os Xetá e seus acervos: memória histórica, política e afetiva (Paraná, Brasil). Comunicação apresentada no $5^{\circ}$ Congresso Internacional de Americanistas. Salamanca (Espanha), julho de 2018.

LIMA, Edilene Coffaci de. De documentos etnográficos a documentos históricos: a segunda vida dos registros sobre os Xetá (Paraná, Brasil). Sociologia \& Antropologia. Revista do Programa de Pós-Graduação em Sociologia e Antropologia da Universidade Federal do Rio de Janeiro.- v.8,n.2. mai.-ago. 2018

MOTA, Lúcio Tadeu. Os índios Xetá na província paranaense (1853-1889). Pós-História. Revista de Pós-Graduação em História, v. 6: 175-189. 1998.

PACHECO DE OLIVEIRA, João. Uma etnologia dos "índios misturados"? Situação colonial, territorialização e fluxos culturais. Mana 4(1). 1998.

PACHECO DE OLIVEIRA, João. O efeito "túnel do tempo" e a suposta inautenticidade. Sociedade e Cultua, v.6, n.2, jul./dez. 2003.

PACHECO DE OLIVEIRA, João. Pacificação e tutela militar na gestão de populações e territórios. Mana, 20(1), 125-161, 2014

PARANÁ. Comissão Estadual da Verdade Teresa Urban. Relatório da Comissão da Verdade - PR Teresa Urban. Paraná: CEV/PR, 2014.

PIRES, Maria Ligia de Moura. Guarani e Kaingang no Paraná: um estudo de relações interétnicas. Dissertação (Mestrado em Antropologia Social) - Universidade de Brasília, 1975.

POLLAK, Michael. Memória e identidade social. Revista Estudos Históricos, Rio de Janeiro: Ed UFRJ, v. 5, n. 10, p. 200-212, 1992. Ribeiro, 1970

RIBEIRO, Darcy. Os índios e a civilização: a integração das populações indígenas no Brasil moderno. $1^{a} e d$. Rio de Janeiro: Civilização Brasileira, 1970. 
SAHLINS, Marshall. O "pessimismo sentimental" e a experiência etnográfica: por que a cultura não é um "objeto" em via de extinção (parte I). Mana, Rio de Janeiro, v. 3, n. 1, p. 41-73, 1997a.

SILVA, Carmen Lucia da. Sobreviventes do Extermínio: uma etnografia das narrativas e lembranças da sociedade Xetá. Dissertação (Mestrado em Antropologia Social) - Universidade Federal de Santa Catarina, 1998.

SILVA, Carmen Lucia da. Em busca da Sociedade Perdida: O trabalho de memória Xetá. Tese (Doutorado em Antropologia Social) - Universidade de Brasília. Brasília, 2003.

SOUZA LIMA, Antonio Carlos. Um Grande Cerco de Paz: Poder Tutelar, Indianidade e Formação do Estado no Brasil. Petrópolis, Vozes, 1995.

VIVEIROS DE CASTRO, Eduardo. A Inconstância da Alma Selvagem. São Paulo. Cosac Naify, 2002.

ZILLI, Ana Clara Ferruda. Os Xetá no acervo do Projeto Memória Indígena (19851989) do Museu de Arqueologia e Etnologia (MAE-UFPR). Monografia (Graduação em Ciências Sociais) - Universidade Federal do Paraná, 2018.

\section{Referências documentais}

ÍNDIOS do Paraná. MAE III.oo8.041.002. Abril de 1987

PIRES, Maria Lygia de Moura; ROJAS, Blanca Guilhermina. Relatório: Projeto Memória Indígena no Paraná. MAE III.oo8.o12.oo1. Curitiba, novembro de 1986.

PIRES, Maria Lygia Moura; WAWRZYNIAK, Sônia Izabel. Relatório - auxílio pesquisa pelo Projeto Memória Indígena no Paraná. MAE III.oo8.014.001. Curitiba, abril de 1989.

PROJETO de pesquisa. In: MAE III.oo8.005.001. 1985?

PROJETO de pesquisa. In: MAE III.oo8.oo3.oo1. Curitiba, julho de 1985a.

PROJETO de pesquisa. In: MAE III.oo8.002.oo1. Julho de 1985b.

PROJETO “Memória Indígena no Paraná". MAE III.oo8.oo7.001. 1989?

ROJAS, Blanca Guilhermina. Relatório bimestral - atividades desenvolvidas pelo Projeto Memória Indígena nos meses de agosto e setembro de 1988. MAE III.oo8.o12.oo1. Curitiba, outubro de 1988. 